\title{
The role of epithelial-mesenchymal transition (EMT)-associated genes during gonadogenesis of albino rat
}

\author{
Lina A. Aeshra', Maiada Moustafa2 $2^{*}$ (D), Mohammed I.Y. Elmallah³ ${ }^{3}$ Said Abdelrahman Salih ${ }^{1}$ and Ibrahim Y. Abdel Kader ${ }^{4}$
}

\begin{abstract}
Background: The epithelial mesenchymal transition (EMT) plays a critical role in normal embryonic development as well as abnormal pathological events such as tumor formation and metastasis. One of these important events that may explain this phenomenon during embryogenesis is the migration of primordial germ cells (PGCs) from hindgut into the genital ridge during gonadogenesis. Yet, more studies are needed to explain the molecular changes underlying the role of EMT during gonadogenesis. Here, we aimed to study the molecular changes of four genes to determine whether the EMT occurs during gonadogenesis. These studied genes are alkaline phosphatase (ALP) as PGC marker, E-cadherin (CDH1) as epithelial marker, vimentin (VIM) as mesenchymal marker, and signal transducer and activator of transcription 3 (STAT3) as migration regulator and differentiation marker.

Results: The results showed a substantial decrease in the expression of ALP by the increase of the embryonic age. The expression of $\mathrm{CDH} 1$ is inversely proportional to the expression of VIM during the days of PGC migration. STAT3 expression related to the time of occurrence of migration and differentiation.

Conclusion: Taken together, our findings demonstrated the molecular changes of ALP, PGC, CDH1, and VIM during the process of gonadogenesis. Further studies are warranted to understand other molecular mechanisms associated with gonadogenesis.
\end{abstract}

Keywords: Gonadogenesis, EMT, MET, Embryogenesis, PGC migration

\section{Introduction}

The development of gonad is a complex process encompassing sexual dimorphic differentiation of somatic and germ cells. The laboratory mice and rats are key models for research in gonadal differentiation, in which precise morphological and cellular changes during the developmental process(es) have been well documented and characterized (Kobayashi \& Kono, 2012; Wilhelm, Palmer, \& Koopman, 2007).

Expression of a set of genes that control germ also involves three main phases, which are primordial germ cell (PGC) specification, PGC migration and differentiation of PGCs (Soto-Suazo \& Zorn, 2005). In the developing of rat embryo, PGCs migrate from the extraembryonic mesoderm into the urogenital ridge and populate the

\footnotetext{
*Correspondence: maiadamoustafa11@gmail.com

${ }^{2}$ Zoology and Entomology Department, Faculty of Science, Helwan

University, Cairo, Egypt

Full list of author information is available at the end of the article
}

gonads between E12.5 to E13. Once inside the gonad, the germ cells continue to proliferate and go through several rounds of mitotic divisions in both sexes. Then the germ cells lose their motility and start to colonize in the gonads (Taketo, Thau, Adeyemo, \& Koide, 1984; Wilhelm et al., 2007; Witschi, 1962). Germ cell specification leads to the expression of a set of genes that control germ cell migration from the posterior primitive streak to the developing gonads. Germ cells start to be specified 2-3 days before the specification of the gonad primordial. Some of the intervening period (E9-E11) is spent lodged in the epithelium of the hindgut. This arises from the posterior definitive endoderm, derived in turn from the primitive streak. From E11-E13, germ cells leave the hindgut and migrate across the intervening mesenchyme to the gonad primordia, where they integrate with gonadal somatic cells, which derived from the intermediate mesoderm, to form the sex cords (El3-E14) (Anderson, 
Copeland, Schöler, Heasman, \& Wylie, 2000; Wylie \& Anderson, 2002).

One of the characteristics of PGCs is that the activity of alkaline phosphatase (ALP) increases (Soto-Suazo \& Zorn, 2005). It is suggested that PGC can actively migrate to the developing gonads, and results from the in vivo observation of pseudopodial structures may led to the conclusion that PGCs migrate by amoeboid movements (Makabe, Naguro, Nottola, Pereda, \& Motta, 1991). This movement represents an example of cell migration, which is a prominent feature of the development of multicellular organisms.

Epithelial-mesenchymal transition (EMT) was originally described in early embryogenesis as an essential process for specific developmental stages that require migration and transient dedifferentiation of embryonic epithelial cells such as gastrulation and migration of neural crest cells (Hay, 1995; Moreno-Bueno et al., 2009). Developmental EMT is a highly dynamic and tightly regulated spatiotemporal process. This is an intricate process by which epithelial cells lose their epithelial characteristics and acquire a mesenchymallike phenotype. This dramatic phenotypic change involves the loss of E-cadherin-mediated cell-cell adhesion and additional prototypic epithelial markers as well as the loss of apical-basal polarity. This occurs concomitantly with the acquisition of a motile behavior and a profound reorganization of the cytoskeleton (Huber, Kraut, \& Beug, 2005). Downregulation of E-cadherin is one of the essential leading event of EMT and is considered as a hallmark of this process, and at present is one of the most reliable markers of EMT (Thiery, 2002).

Vimentin is the major intermediate filament protein found in mesenchymal cells, as it is frequently used as a developmental marker of cells and tissues (Eriksson et al., 2009). Therefore, vimentin is often used as a marker of mesenchymally derived cells or cells undergoing an epithelial-to-mesenchymal transition (EMT) during normal embryonic development.

STAT3 is a member of the signal transducer and activator of transcription family, which is important for cytokine signaling as well as for a number of cellular processes including cell proliferation, anti-apoptosis and immune responses (Takeda, 1997). The Janus kinase-signal transducer and activator of transcription (JAK-STAT) signaling is crucial in chicken germ stem cell differentiation; however, its role in the regulation of germ cell differentiation is unknown (Teng, Lin, Manser, Ng, \& Cao, 2009).

\section{Materials and methods Animal study}

All procedures were performed as a part of an approved scientific protocol CU-I-S-1-16 in accordance with the University of Cairo Institutional Animal Care and Use Committee (CU-IACUC).
Animals were kept at regular food and temperature for at least 1 week before performing any experiment. Time mating was used to determine the date of conception and gestational stage of pregnant rats. One male and two females were placed together in one cage, at the end of the working day (approximately 4 PM) in order to allow mating to take place overnight. The next morning, the male would then be removed and the female housed separately and vaginal smears were examined.

\section{RNA extraction and real-time PCR (qPCR)}

Total RNA from embryos was extracted using miRNeasy Mini Kit following the manufacturer's protocol (Qiagen, Cat. no. 217004, Germany). Reverse transcription was performed using the High Capacity cDNA Reverse Transcription Kit as described by the manufacturer's guideline (Applied Biosystems, Foster City, CA, Cat. no. 4374966). Real-Time PCR was performed using a thermal cycler (QuantStudio ${ }^{\text {tix }}$ Real-Time, Applied Biosystems). The parameters of the thermal cycling of the PCR reaction were adjusted as follows: $15 \mathrm{~s}$ at $95^{\circ} \mathrm{C}, 1 \mathrm{~min}$ at $60{ }^{\circ} \mathrm{C}$, for 50 cycles. Analysis of gene expression was performed according to $2^{-\Delta \Delta C T}$ method (Livak \& Schmittgen, 2001) and gapdh was used as a house keeping gene.

\section{Primer design}

Alkaline phosphatase (ALP), E-cadherin (CDH1), vimentin (VIM), signal transducer and activator of transcription 3 (STAT3), and glyceraldehyde 3-phosphate dehydrogenase (gapdh) were considered for gene expression analysis in Rattus norvegicus albinus. The primers were designed using Oligo7 based on the available RNA sequences of $R$. norvegicus (Genbank accession numbers; shown in Table 1). All primers were purchased from Eurofins Genomics.

\section{Statistical analysis}

Data are presented as mean \pm standard errors of the means (S.E.M). Comparison of data was performed using one-way analysis of variance (ANOVA) followed by Tukey-Kramer's multiple comparison test (Armitage, 1978) using prim version 5 . The significance of data was considered when $P<0.05$.

\section{Results}

The gene expression patterns of Alkaline phosphatase (ALP), E-Cadherin (CDH1), Vimentin (VIM), and signal transducer and activator of transcription 3 (STAT3) have been analyzed at five different stages from E9.5 to E 13.5. These five stages represent the phases of PGC migration from the hindgut to the genital ridge. To examine such molecular changes on the level of gene expression, we assess the gene expression pattern during five different embryonic stages. 
Table 1 The primer sequences, Alp, E-Cad, Vim, STAT3, and gapdh were purchased from the manufacturer Eurofins Genomics

\begin{tabular}{|c|c|c|c|c|}
\hline Gene & & Accession number & $\begin{array}{l}\text { Forward primer (FW) }\left(5^{\prime}-3^{\prime}\right) \text { and } \\
\text { Reverse primer (RV) }\left(5^{\prime}-3^{\prime}\right)\end{array}$ & $\begin{array}{l}\text { Product size } \\
\text { (bp) }\end{array}$ \\
\hline ALP & Alkaline phosphatase & NM_013059.1 & $\begin{array}{l}\text { FW: Ctgctgatcactcccacgttt } \\
\text { RV: Gttctcccgttcaccgtccac }\end{array}$ & 164 \\
\hline $\mathrm{E}-\mathrm{CAD}$ & E-cadherin & NM_031334.1 & $\begin{array}{l}\text { FW: Catgccccagtatcgtccc } \\
\text { RV: Actcccctcatagtcaaacacc }\end{array}$ & 136 \\
\hline VIM & Vimentin & NM_ 031140.1 & $\begin{array}{l}\text { FW: Caaacgaataccggagacagg } \\
\text { RV: Agttagcagcttcaagggcaa }\end{array}$ & 126 \\
\hline STAT3 & Signal transducer and activator of transcription 3 & NM_012747.2 & $\begin{array}{l}\text { FW: Ggctagacaatatcatcgacct } \\
\text { RV: Ttgctgctctcactgaaccg }\end{array}$ & 154 \\
\hline GAPDH & Glyceraldehyde 3-phosphate dehydrogenase & NM_017008.4 & $\begin{array}{l}\text { FW: tgccactcagaagactgtgg } \\
\text { RV: ggatgcagggatgatgttct }\end{array}$ & 85 \\
\hline
\end{tabular}

The four studied genes are expressed in the five different embryonic stages. At E9.5 and E10.5, ALP expression was significantly upregulated as an initial PGC marker, while its expression level during the days E11.5 to E13.5 was dramatically decreased (over 90\%; Fig. 1).

No significant changes in the expression level of CDH1 from E9.5 to E10.5 was detected. However, its expression was significantly enhanced at E11.5 and E13.5. Conversely, the expression level of CDH1 was significantly declined at E12.5 (Fig. 2).

Considering the gene expression analysis of VIM, no significant difference in the expression level between E9.5 and E12.5 was reported. However, the expression of this mesenchymal marker was obviously upregulated at E10.5, E11.5, and E13.5 compared to E9.5 (Fig. 3).

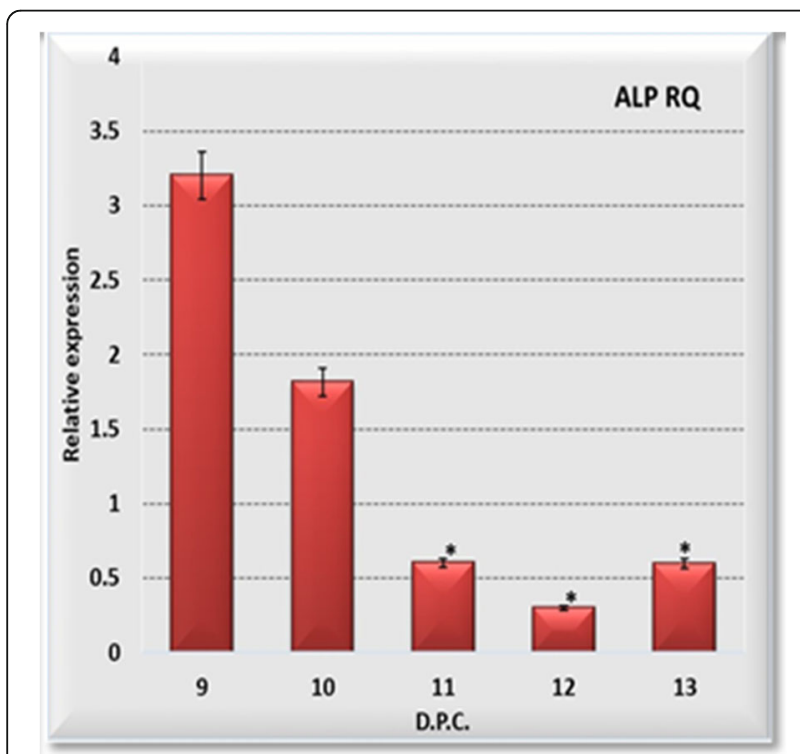

Fig. 1 Histogram representing the gene expression of Alkaline phosphatase (ALP), at the embryonic stages E9.5 to E13.5 of rat embryos (Rattus norvegicus).* means significant against 9 D.P.C. group. $P<0.05$
A slight increase in the expression level of STAT3 at E10.5, however, a significant increase in its expression was detected at E11.5, which gives a slight indication for the importance of STAT3 in migration, cell growth, and cell differentiation. In contrast, the expression level of STAT3 was significantly decreased at E12.5 (Fig. 4).

\section{Discussion}

PGCs in rat are found in the proximal epiblast close to the extraembryonic ectoderm at E8 (Matsui, 2010). Then it translocates to extraembryonic mesoderm at the base of the amniotic fold, while most are still embedded in the epithelium of the developing hindgut at E9-E10. The migration of embryonic PGCs out of the hindgut begins at E11.5 and the cells arrive to their destination

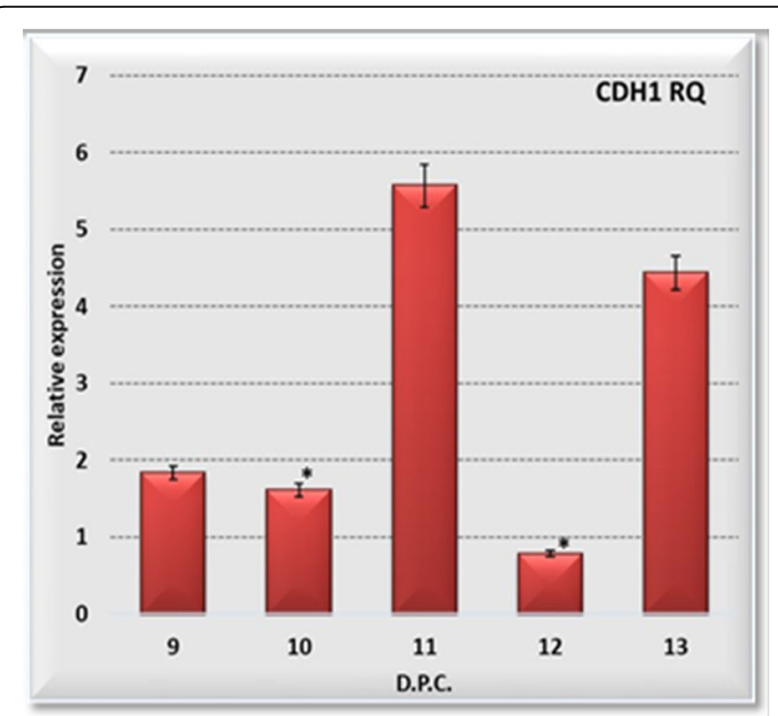

Fig. 2 Histogram representing the gene expression of Alkaline phosphatase $(\mathrm{CDHI})$, at the embryonic stages E9.5 to E13.5 of rat embryos (Rattus norvegicus).* means significant against 11 D.P.C. group. $P<0.05$ 


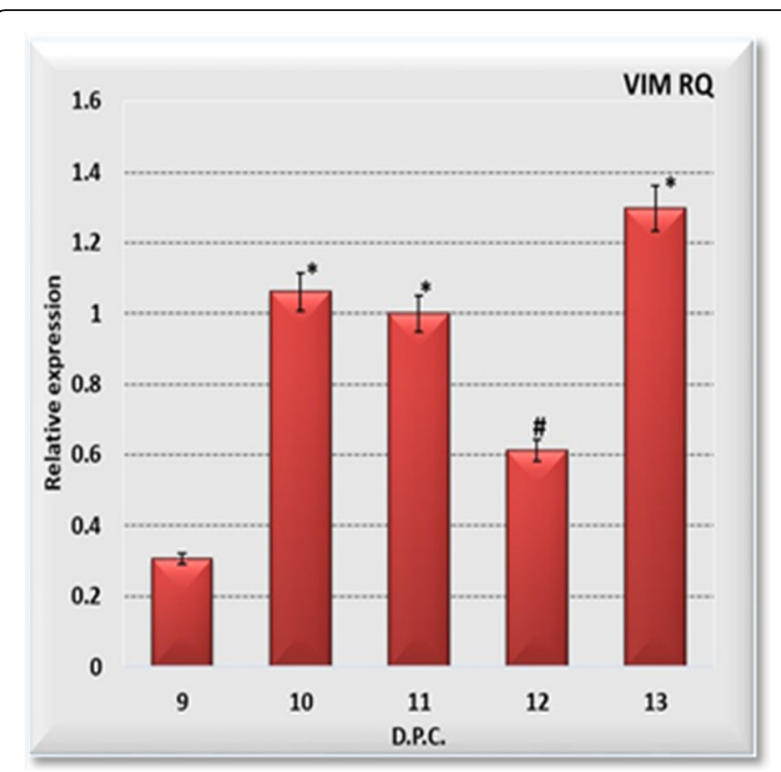

Fig. 3 Histogram representing the gene expression of Vimentin (VIM), at the embryonic stages E9.5 to E13.5 of rat embryos (Rattus norvegicus).* means significant against 13 D.P.C. group. $P<0.05$

at E12.5-E13 where they begin to differentiate (Kemper \& Peters, 1987). A set of genes that may be related to EMT studied in this work might regulate the migration behavior of PGCs. There are many molecules, factors, mediators, and signaling pathways that are involved in the EMT process. A hallmark of EMT is the loss of E-cadherin expression. E-cadherin is a cell-cell adhesion molecule that participates in homotypic, calcium-dependent interactions

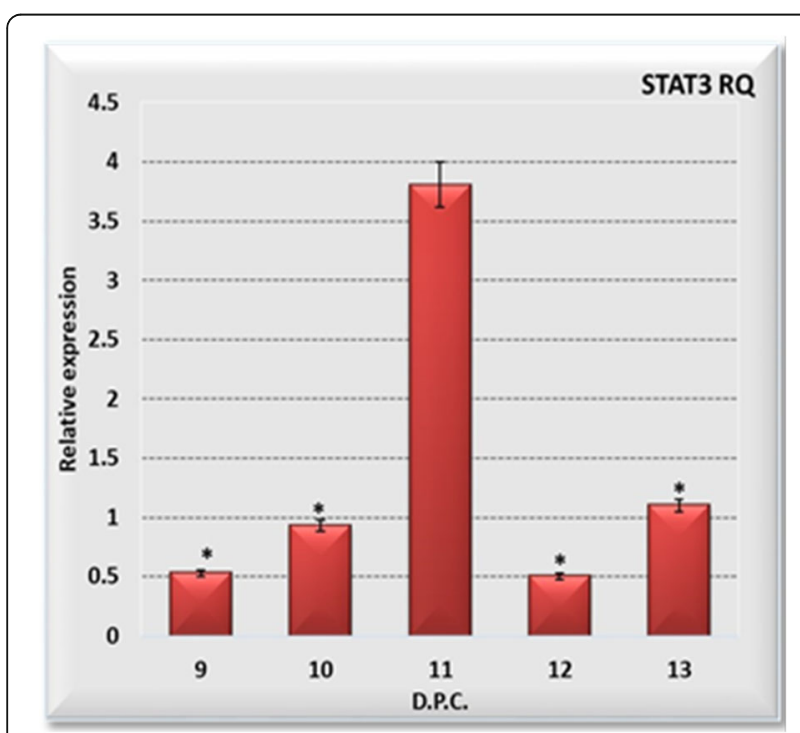

Fig. 4 Histogram representing the gene expression of signal transducer and activator of transcription 3 (STAT3), at the embryonic stages E9.5 to E13.5 of rat embryos (Rattus norvegicus).* means significant against 11 D.P.C. group. $P<0.05$ to form epithelial adherent junctions (Thiery, 2002; Wu \& Zhou, 2008). In our results, the significant upregulation of ALP at E9.5 may be due to the specification and proliferation of PGCs before their migration. At the same time, the low expression of STAT3 may refer to the pre-migration phase. Obviously, PGCs are epithelial in nature because of the high expression of $\mathrm{CDH} 1$ and low expression of Vim at E10.5. Cell-cell adhesion and subsequent aggregation may play a role in the integration of PGCs into the genital ridges (Gomperts, Garcia-Castro, Wylie, \& Heasman, 1994; Molyneaux, Stallock, Schaible, \& Wylie, 2001). The expression profile of CDH1and VIM during the migration phase of PGC may suggest that these cells mimic cells during EMT and MET phenomena. The downregulation of ALP as PGCs marker suggests that the transformation of PGCs as epithelial cells into mesenchymal-like cells to increase the migratory capacity of these cells. It has been reported that STAT3 is required to mediate conversion of PGCs to embryonic germ cells (Leitch et al., 2013). It was suggested that JAK-STAT effectively promoted the formation of PGCs in the genital ridge during early embryogenesis in vivo and played a positive role in the regulation of embryonic stem cells (ESC) to somatic stem cells (SSC) differentiation in vitro (Zhang et al., 2017). Recently, there is an emerging evidence on the importance of STAT3 in regulating cell migration; motility and invasion in physiological and pathological conditions (Teng et al., 2009). STAT3 has also drawn attention because of its capacity to induce cellular transformation (Bromberg, Horvath, Besser, Lathem, \& Darnell, 1998). These findings may explain the slight increase of STAT3 expression at E10.5 as a transformation inducer of PGCs into mesenchymal-like cells. At E11.5, the expression of STAT3 markedly increased, which suggests its role in PGC movement out of hindgut to the genital ridge. The decline expression of STAT3 at E12.5, at which the migrating PGCs reach the genital ridge, may explain the end of the PGC movements. At E12.5, the downregulation of $\mathrm{CDH} 1$ and Vimentin prompted us to suggest that PGCs have the ability to retract their mesenchymal phenotype back to its epithelial nature. However, more studies are required to validate this assumption.

At the beginning of PGC migration in the rat from the hindgut at E9.5, the upregulation of PGC marker (ALP) and epithelial marker (CDH1) confirming that PGCs are epithelial in their nature. Simultaneously, the significant upregulation of the mesenchymal marker (VIM) and the relevant downregulation of $\mathrm{CDH} 1$ at E10.5 suggests that some of these cells lost their epithelial characteristics and acquainted the mesenchymal features.

\section{Conclusion}

These findings corroborate the theory of PGCs which have the capability to acquire the EMT phenotype during 
their migration to the genital ridge. Before the time of E12.5, PGCs reaching their destination, the STAT3 is upregulated, which suggests that it plays a role in the sex differentiation of the gonad. At this stage, $\mathrm{CDH} 1$ is slightly upregulated which implies the role of this gene in the aggregation of PGCs to form a gonad inside the genital ridge. More studies are needed to confirm that the EMT phenomenon is related to the expression of the epithelial, mesenchymal, PGCs, migration, and differentiation markers during gonadogenesis.

\section{Abbreviations \\ ALP: Alkaline phosphatase; CDH1: E-cadherin; EMT: The epithelial mesenchymal transition; PGCs: Primordial germ cells; STAT3: Signal transducer and activator of transcription 3; VIM: Vimentin}

\section{Acknowledgements}

The authors acknowledge the Medical Research Centre, Faculty of Medicine, Ain Shams University for their helpful and valuable advice in this work.

\section{Authors' contributions}

LAA is responsible for animal handling and experimental procedures and shared in manuscript writing. MM put the idea of the work, shared in study designing, and carried out the statistical analysis of data and manuscript writing. ME and SAS shared in manuscript editing. IYAK shared in study designing and manuscript editing. All authors read and approved the final manuscript.

\section{Funding}

No funding was provided.

\section{Availability of data and materials}

All data are available upon request.

\section{Ethics approval and consent to participate}

All procedures were performed as a part of an approved scientific protocol CU-I-S-1-16 in accordance with the University of Cairo Institutional Animal Care and Use Committee (CU-IACUC).

\section{Consent for publication}

The data provided here are original.

\section{Competing interests}

The authors declare that they have no competing interests.

\section{Author details}

'Chemistry Department, Faculty of Science, Cairo University, Cairo, Egypt. ${ }^{2}$ Zoology and Entomology Department, Faculty of Science, Helwan University, Cairo, Egypt. ${ }^{3}$ Chemistry Department, Faculty of Science, 11795 Ain Helwan, Cairo, Egypt. ${ }^{4}$ British University, Cairo, Egypt.

Received: 19 July 2019 Accepted: 27 December 2019

Published online: 20 January 2020

\section{References}

Anderson, R., Copeland, T. K., Schöler, H., Heasman, J., \& Wylie, C. (2000). The onset of germ cell migration in the mouse embryo. Mechanisms of Development, 91(1-2), 61-68.

Armitage, P. (1978). Statistical methods in medical research.

Bromberg, J. F., Horvath, C. M., Besser, D., Lathem, W. W., \& Darnell, J. E. (1998). Stat3 activation is required for cellular transformation by v-src. Molecular and Cellular Biology, 18(5), 2553-2558.

Eriksson, J. E., et al. (2009). Introducing intermediate filaments: from discovery to disease. The Journal of Clinical Investigation, 119(7), 1763-1771.

Gomperts, M., Garcia-Castro, M., Wylie, C., \& Heasman, J. (1994). Interactions between primordial germ cells play a role in their migration in mouse embryos. Development, 120(1), 135-141.
Hay, E. D. (1995). An overview of epithelio-mesenchymal transformation. Acta Anatomica (Basel), 154(1), 8-20.

Huber, M. A., Kraut, N., \& Beug, H. (2005). Molecular requirements for epithelialmesenchymal transition during tumor progression. Current Opinion in Cell Biology, 17(5), 548-558.

Kemper, C. H., \& Peters, P. W. (1987). Migration and proliferation of primordial germ cells in the rat. Poultry Science, 86, 2182-2193.

Kobayashi, H., \& Kono, T. (2012). Germline development. Methods, 825, 223-235.

Leitch, H. G., et al. (2013). Rebuilding pluripotency from primordial germ cells. Stem Cell Reports, 1(1), 66-78.

Livak, K. J., \& Schmittgen, T. D. (2001). Analysis of relative gene expression data using real-time quantitative PCR and the $2-\Delta \Delta C T$ method. Methods, 408, 402-408.

Makabe, S., Naguro, T., Nottola, S. A., Pereda, J., \& Motta, P. M. (1991). Migration of germ cells, development of the ovary, and folliculogenesis. In Ultrastructure of the ovary, (pp. 1-27). Boston: Springer US.

Matsui, Y. (2010). The molecular mechanisms regulating germ cell development and potential. Journal of Andrology, 31(1), 61-65.

Molyneaux, K. A., Stallock, J., Schaible, K., \& Wylie, C. (2001). Time-lapse analysis of living mouse germ cell migration. Developmental Biology, 240(2), 488-498.

Moreno-Bueno, G., et al. (2009). The morphological and molecular features of the epithelial-to-mesenchymal transition. Nature Protocols, 4(11), 1591-1613.

Soto-Suazo, M., \& Zorn, T. (2005). Primordial germ cells migration: morphological and molecular aspects. Animal Reproduction, 2, 147-160.

Takeda, K. (1997). Targeted disruption of the mouse Stat 3 gene leads to early embryonic lethality. Developmental Biology, 94(April), 3801-3804.

Taketo, T., Thau, R. B., Adeyemo, O., \& Koide, S. S. (1984). Influence of adenosine $3^{\prime}: 5^{\prime}$-cyclic monophosphate analogues on testicular organization of fetal mouse gonads in vitro. Biology of Reproduction, 30(1), 189-198.

Teng, T. S., Lin, B., Manser, E., Ng, D. C. H., \& Cao, X. (2009). Stat3 promotes directional cell migration by regulating Rac1 activity via its activator PIX. Journal of Cell Science, 122(22), 4150-4159.

Thiery, J. P. (2002). Epithelial-mesenchymal transitions in tumour progression. Nature Reviews Cancer, 2(6), 442-454.

Wilhelm, D., Palmer, S., \& Koopman, P. (2007). Sex determination and gonadal development in mammals. Physiological Reviews, 87(1), 1-28.

Witschi, E. (1962). Development: rat. In P. L. Altmann, \& D. S. Dittmer (Eds.) Biological handbook of federation of American societies for Experimental Biology, (pp. 304-314). Washington, D.C: Federation of American Societies for Experimental Biology

Wu, Y., \& Zhou, B. P. (2008). New insights of epithelial-mesenchymal transition in cancer metastasis. Acta Biochimica et Biophysica Sinica, 40(7), 643-650.

Wylie, C., \& Anderson, R. (2002). Germ cells.

Zhang, Y., et al. (2017). JAK-STAT signaling regulation of chicken embryonic stem cell differentiation into male germ cells. In Vitro Cellular \& Developmental Biology-Animal, 53(8), 1-16.

\section{Publisher's Note}

Springer Nature remains neutral with regard to jurisdictional claims in published maps and institutional affiliations.

\section{Submit your manuscript to a SpringerOpen ${ }^{\circ}$ journal and benefit from:}

- Convenient online submission

- Rigorous peer review

- Open access: articles freely available online

- High visibility within the field

- Retaining the copyright to your article

Submit your next manuscript at $\boldsymbol{\nabla}$ springeropen.com 